\title{
中国-日本植物区系中的谱系地理间断及其形成机制
}

\author{
叶俊伟 ${ }^{1,2}$ 张 阳 ${ }^{1}$ 王晓娟 ${ }^{1 *}$
}

${ }^{1}$ 上海科技馆上海自然博物馆自然史研究中心, 上海 200127; ${ }^{2}$ 华东师范大学生命科学学院, 上海城市化生态过程与生态恢复重点实验室, 上海 200062

摘 要 中国-日本植物区系极高的物种多样性是由多样的地形和气候条件、复杂的地质气候历史和海平面变化共同作用形 成的。在揭示物种多样性形成和分化的驱动力时, 谱系地理学是一个有效的手段。以往的谱系地理研究表明谱系地理间断, 即 不同基因谱系间的间断普遍存在。由西向东, 7 个普遍存在的谱系地理间断位置位于湄公河-怒江分水岭、田中-楷永线、四川 盆地、 $105^{\circ} \mathrm{E}$ 附近、第二三阶梯分界线、华北地区以及东海和朝鲜海峡。这些谱系地理间断的形成可归因于历史因素和生态 因素, 往往由地理隔离和环境隔离共同起作用。历史因素是地质事件和气候变化, 主要包括青藏高原隆起, 亚洲季风和内陆 干旱的形成与增强, 干旱带的重新增强以及第四纪的气候波动和海平面变化。生态因素是适应性分化, 即不同环境中不同选 择压力下形成的分化, 适应性分化可阻碍不同种群间的基因流, 形成谱系地理间断。不过, 同一谱系地理间断并不是在所有 植物中共享, 因为不同植物有不同的生物学特性, 主要是扩散能力不同。最后, 该文从分化时间的准确估计、地理隔离和环 境隔离的相对贡献率以及比较谱系地理学的应用 3 个方面对未来谱系地理间断研究的发展趋势进行了展望。

关键词 中国-日本植物区系; 谱系地理间断; 地质气候变化; 适应性分化; 扩散能力

引用格式: 叶俊伟, 张阳, 王晓娟 (2017). 中国-日本植物区系中的谱系地理间断及其形成机制. 植物生态学报, 41, 1003-1019. doi: 10.17521/cjpe.2016.0388

\section{Phylogeographic breaks and the mechanisms of their formation in the Sino-Japanese floristic region}

YE Jun-Wei ${ }^{1,2}$, ZHANG Yang ${ }^{1}$, and WANG Xiao-Juan ${ }^{1 *}$

${ }^{1}$ Natural History Research Center of Shanghai Natural History Museum, Shanghai Science \& Technology Museum, Shanghai 200127, China; and ${ }^{2}$ Shanghai Key Laboratory of Urbanization \& Ecological Restoration, School of Life Sciences, East China Normal University, Shanghai 200062, China

\section{Abstract}

Due to combinations of diverse geography and climate, and complex geo-climate histories and sea level fluctuations, the Sino-Japanese floristic region has extremely high species diversity. Phylogeography is an effective method to identify the factors triggering the formation and differentiation of species diversity. Previous studies showed that phylogeographic breaks, the genetic discontinuity between different gene genealogies, were ubiquitously present. From the west to the east, seven general phylogeographic breaks occur, including the MekongSalween Divide, the Tanaka-Kaiyong Line, the Sichuan Basin, $c a .105^{\circ}$ E, the boundary between the Second and Third ladders, the North China, and the East China Sea and Korea Strait. These phylogeographic breaks are mainly attributable to both historical and ecological factors, which are generally due to a combined effect of the isolation by distance (IBD) and the isolation by environment (IBE). Geological events and climate changes are the historical factors, mainly including the uplift of Qinghai-Xizang Plateau, the formation and intensification of the Asian monsoon and the Asian interior aridification, the redevelopment of the arid belt, and the Quaternary climate oscillations and sea level fluctuations. Adaptive divergence, namely the divergence induced by different selective pressures under different environments, is responsible for the ecological factors. Adaptive divergence could obstacle gene flow among populations, resulting in the formation of phylogeographic break. However, an identical phylogeographic break is not shared by all the plants because of their various intrinsic biological characteristics, among which the difference in dispersal ability is most important. Finally, we envisaged the future development of phylogeographic break studies based on accurate divergence time estimation, relative contribution of IBD and IBE, and also the utilization of comparative phylogeography.

Key words Sino-Japanese floristic region; phylogeographic break; geo-climate change; adaptive evolution; dispersal ability

收稿日期Received: 2016-12-19 接受日期Accepted: 2017-06-01

* 通信作者Author for correspondence (E-mail: wangxj@sstm.org.cn) 
Citation: Ye JW, Zhang Y, Wang XJ (2017). Phylogeographic breaks and the mechanisms of their formation in the Sino-Japanese floristic region. Chinese Journal of Plant Ecology, 41, 1003-1019. doi: 10.17521/cjpe.2016.0388

中国-日本植物区系(SJFR)为全北植物区的一 个区系(图1), 是北半球温带植物区系中物种多样性 最高的区域，其物种数大约是面积和环境相似的北 美东部植物区系的2倍(Qian \& Ricklef, 2000)。Qian 和Ricklef (2000)认为多样的地形和气候条件、复杂 的地质气候历史和海平面变化对中国-日本植物区 系中高水平物种多样性的形成和维持有重要作用。 随后，一些研究通过化石孢粉数据模拟了过去和现 在的植被分布(Yu et al., 2000; Harrison et al., 2001; $\mathrm{Ni}$ et al., 2010)。Harrison等(2001)通过末次冰盛期 (Last Glacial Maximum, LGM, 26 000-19 000年前) 和现在的植被重建, 发现温带和亚热带森林均在末 次冰盛期时明显向南退缩, 冰期后明显向北扩张至
现在的分布区。Yu等(2000)和 $\mathrm{Ni}$ 等(2010)也发现了类 似的迁移模式。植被重建可比较不同时期(如LGM) 与现在不同植被类型的空间变化，但无法判断不同 群落间的遗传关系，也不能全面地认识物种形成和 分化的历史及其成因。谱系地理学(phylogeography) 重点研究种内或近缘种内基因谱系(gene genealogy) 的空间格局及其形成过程，可探讨生物类群对历史 地质事件和气候变化的响应模式(Avise, 2000, 2009; Hickerson et al., 2010)。因此, 谱系地理学可研究植 物对多样的地形和气候条件、复杂的地质气候历史 和海平面变化的响应模式, 是探究种群分化或物种 形成驱动力的有力工具。

谱系地理研究中使用的常常是中性分子标记,

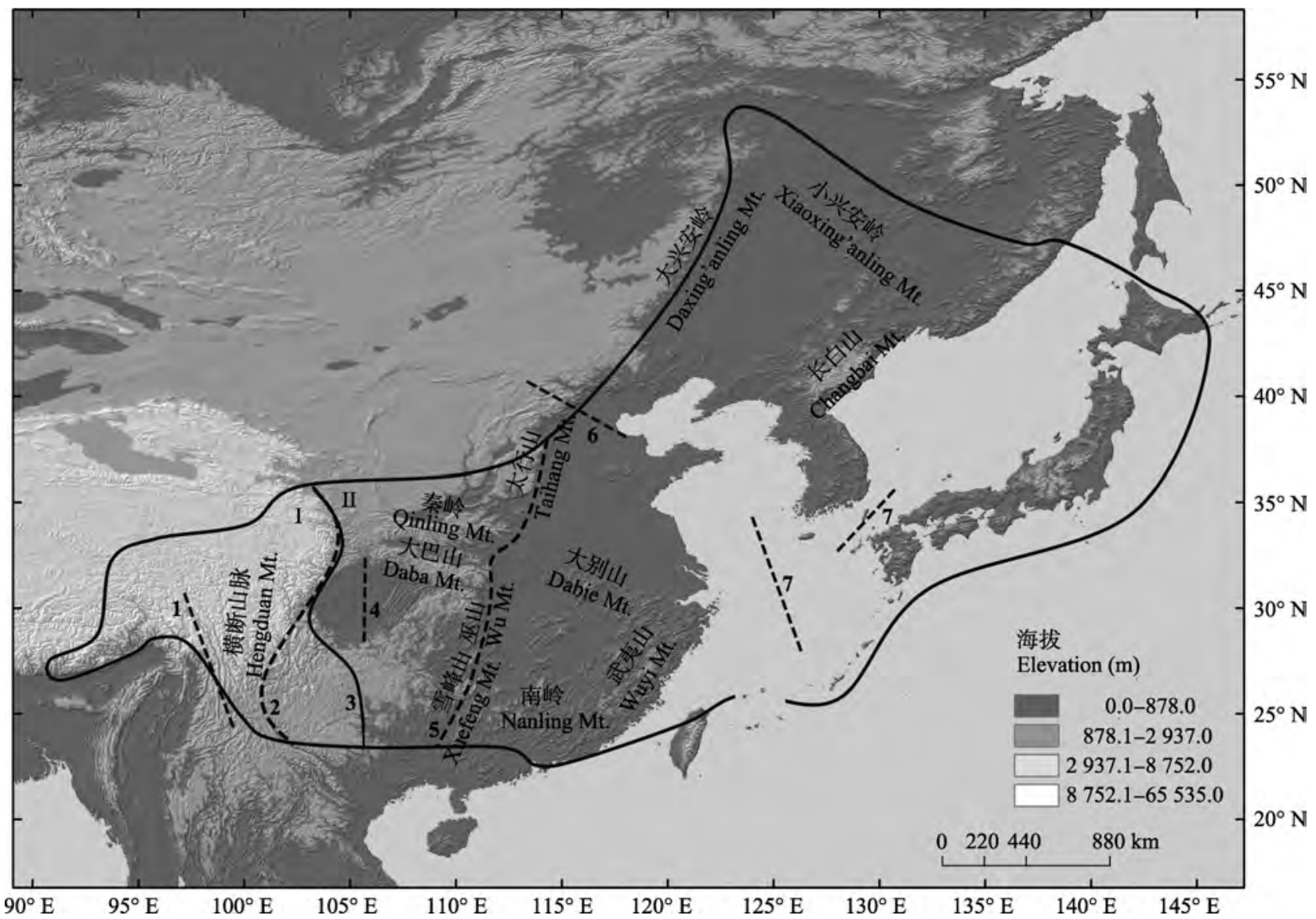

图1 中国-日本植物区系和谱系地理间断位置。实线为中国-日本植物区系及两个亚区的边界线(Wu \& Wu, 1996): (I)中国-喜 马拉雅植物亚区, (II)中国-日本植物亚区。虚线为 6 个谱系地理的位置: 1 , 湄公河-怒江分水岭; 2 , 田中-楷永线; 4, 四川盆地; 5, 第二三阶梯分界线; 6 ，华北地区; 7 ，东海和朝鲜海峡。实线3表示的谱系地理间断在 $105^{\circ} \mathrm{E}$ 附近。

Fig. 1 The Sino-Japanese floristic region and locations of phylogeographic breaks. Solid lines indicate the boundaries of two floristic subkingdoms (Wu \& Wu, 1996): (I) Sino-Himalayan forest subkingdom, (II) Sino-Japanese forest subkingdom. Dotted lines are the six phylogeographic breaks: 1, Mekong-Salween Divide; 2, Tanaka-Kaiyong Line; 4, Sichuan Basin; 5, boundary of the Second and Third ladders; 6, North China; 7, East China Sea and Korea Strait. Solid line 3 indicates the phylogeographic break of $c a .105^{\circ}$ E. 
如叶绿体基因、核微卫星和转录间隔区等。然而, 许 多植物的基因谱系并不如预期的在地理空间上随机 分布, 而是在地理空间上与气候、环境因子或表型 性状等有很好的对应关系, 不同基因谱系间的间断 即是谱系地理间断(phylogeographic break)(郭希的 等, 2015)。以往的谱系地理研究往往侧重关注冰期 避难所位置以及避难所种群在间冰期或冰期后种群 扩张中起到的作用(Qiu et al., 2011; Liu et al., 2012)。Qiu等(2011)展示了4个谱系地理间断, 之后 的研究工作同样包含了地质气候变化和环境差异等 对谱系分化和谱系地理间断位置影响的讨论。然而, 未见谱系地理间断位置及其形成机制的系统阐述。 谱系地理间断在种群分化中可阻碍基因流, 长时间 基因流的缺失可提高遗传分化, 导致生殖隔离, 最 终形成新的物种(Coyne \& Orr, 2004)。

因此, 对谱系地理间断位置及其形成机制的综 述研究可望对种群分化与物种形成, 乃至生物多样 性的形成和维持机制有更深刻的理解。本文将首先 总结7个普遍的谱系地理间断位置, 然后从历史因 素和生态因素两个方面阐述谱系地理间断的形成机 制, 最后, 从对分化时间的准确估计、地理隔离和环 境隔离的相对贡献率, 以及比较谱系地理学的应用 3 个方面对未来谱系地理间断研究的发展趋势进行 了展望。

\section{1 谱系地理间断位置}

谱系地理间断是不同基因谱系间的基因流屏障， 地理隔离或不同环境产生的适应性分化均可作为基 因流屏障。谱系地理间断两侧的不同基因谱系在有 限的基因流下发生分化, 持续的分化使基因谱系从 多系(polyphyly)演变到并系(paraphyly), 最终形成 单系群 (monophyly), 或进一步形成新的物种 (Hickerson et al., 2010), 在二次接触时, 基因流的 恢复会形成接触区(contact zone)。在中国-日本植物 区系中, 自西向东的7个谱系地理间断位置位于涺 公河-怒江分水岭、田中-楷永线、四川盆地、 $105^{\circ} \mathrm{E}$ 附近、第二三阶梯分界线、华北地区和东海和朝鲜 海峡(图1)。

\section{1 湄公河-怒江分水岭}

南北走向的涺公河-怒江分水岭(MSD)将青藏 高原南部和东南部分隔成东喜马拉雅和横断山两个 山系, 是一条著名的生物地理学分界线。MSD作为
谱系地理间断, 首先在西藏红豆杉(Taxus wallichiana)中发现, 西藏红豆杉包含3个变种(Gao et al., 2007), 广泛分布于西南和亚热带及周边地区的中 海拔林下。Gao等(2007)使用叶绿体基因, 发现基于 单倍型频率的遗传分化 $\left(N_{\mathrm{ST}}\right)$ 显著高于基于单倍型 频率和相似度的遗传分化 $\left(G_{\mathrm{ST}}\right)$, 表明西藏红豆杉存 在明显的谱系地理格局, 其中最显著的谱系地理间 断位于MSD, 将东喜马拉雅和横断山脉种群隔开。 Liu等(2013a)进一步发现西藏红豆杉东西部种群的 分化由地理隔离和环境差异共同导致: MSD北部的 怒山山脉可阻碍东西部种群间的基因流，同时，西 藏红豆杉可能已对西部(温暖湿润)和东部(寒冷干燥) 的不同气候产生了适应，从而形成形态上的差异。 $\mathrm{Li}$ 等(2011)研究了主要分布于 MSD周边桃儿七 (Sinopodophyllum hexandrum)不同种群的扩增片段 长度多态性和叶绿体基因变异, 表明喜马拉雅和横 断山地区的桃儿七种群在第四纪冰期时是原地 (in situ)保留的, 冰期后, 除交界区外, 两个区域的种 群间没有基因交流。通过分化时间估计和古地理学 证据, $\mathrm{Li}$ 等(2011)认为冰期和间冰期时 MSD地区的 高山冰川可能触发了桃儿七替代种(vicariant)的分 化, 并阻碍了分化种群间的基因流。然而, 在喜马拉 雅和横断山区特有的多年生草本植物中华山蓼 (Oxyria sinensis)中, Meng等(2015)发现中华山蓼叶 绿体基因的3个谱系的地理分布与MSD的位置并无 相关性, 不同谱系的分化时间为 $0.86 \mathrm{Ma}$ ，与第四纪 冰期有很好的吻合，且明显晚于MSD形成的时间， 表明冰期时的冰川可能是形成谱系分化的诱因, 而 不是地理隔离。间冰期时中华山蓼种群的扩张和二 次接触事件重构了遗传格局, 降低了由于冰川阻碍 而形成的遗传分化。因此，中华山苶不同基因谱系 的形成与MSD并无相关性。通过分化时间估计和环 境差异分析, 中华山苶和桃儿七是因MSD不适宜的 环境(冰川)触发了不同谱系的形成和分化, 西藏红 豆杉的分化是由于地理隔离和环境差异导致。因此, 地理隔离和环境差异在谱系地理间断MSD形成中 的相对重要性尚不明确, 需要更深入的研究。

作为生物多样性热点的喜马拉雅-横断山地区 (Myers et al., 2000), 除MSD外，另外一个显著特征 是富有 “天空之岛”, 即高海拔山区的气候、植被和 生物与周边低海拔的不同, 形似“岛屿” (何锴和蒋 学龙, 2014)。在活跃的地质活动以及极其复杂多样 
的地形和环境下，高山植物通过适应性辐射 (adaptive radiation), 在短时间内形成高水平的物种 多样性(Hughes \& Atchison, 2015)。如该地区的杜鹃 属(Rhododendron)、报春花属(Primula)、马先蒿属 (Pedicularis)和龙胆属(Gentiana) 等都发生了高度的 分化与特化。并且, 本区域物种种群分化、杂交、 突变等进化现象明显, 是研究植物进化和新种起源 过程的天然实验室。

\section{2 田中-楷永线}

田中-楷永线(Tanaka-Kaiyong Line, TKL)是位 于中国西南部的一条分界线, 由位于云南地区的 田中线(Tanaka, 1954)和位于四川的楷永线(郎楷永, 1994)组成。李锡文和李捷(1992)首先发现云南分布 的东亚植物属中 108 个属的分布在田中线两侧有明 显差异, 表明了田中线的重要性。除云南分布的东 亚属外, 田中线对云南地区中国特有属的分布也有 明显的限制作用(冯建孟和朱有勇, 2010)。 Li和 $\mathrm{Li}$ (1997)提出历史和生态过程的共同作用是TKL的成 因, 历史过程是青藏高原的隆起, 生态过程是 TKL 两侧不同的气候(西侧为印度和太平洋季风, 东侧 主要为太平洋季风)。这两个成因在时间尺度上并不 重合, 青藏高原在中新世中期和上新世晚期有明显 的隆起(Zhou et al., 2006; Royden et al., 2008), 而 TKL 两侧不同的季风是在更新世形成的(Wang, 1994)。因此, 通过分化时间的估计可推断历史和生 态过程在TKL形成中的相对作用。Fan等(2013)使用 叶绿体基因, 发现白刺花(Sophora davidii)在TKL两 侧为两个不同的基因谱系, 分化时间为 $1.28 \mathrm{Ma}$, 支 持TKL作为气候屏障作用于东西部种群分化的形成 和维持。不过, 叶绿体和核基因均揭示了西部种群 存在向东扩张的历史动态, 表明TKL不能完全隔 离两侧种群。因此, TKL 并不像 “经典”的生物地理 隔离, 通过 “哑铃模型” (dumbell model)(Coyne \& Orr 2004), 在隔离的两侧促使新物种的形成。箭根 薯(Tacca chantrieri)在田中线两侧谱系的分化时间 也在更新世(Zhao \& Zhang, 2015)。木棉(Bombax ceiba)田中线两侧的种群并非两个互为单系的类群, 表明了木棉的进化历史仍较短, 不完全的谱系分选 使得两侧仍有叶绿体单倍型的共享，同样不支持历 史过程假说(Tian et al., 2015)。那么, TKL两侧不同 的环境可能作为遗传屏障, 驱动并维持或强化了不 同谱系间的分化。因此, TKL 并不像 “经典” 的生物地
理分界线那样完全阻碍两侧的基因交流。

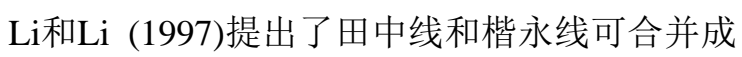
$\mathrm{TKL}$ 。然而, 相比于楷永线, 田中线得到了更多关 注。楷永线是基于木兰科一些属或亚属的分布模式 提出来的, 自郎楷永(1994)之后就少有研究。谱系地 理工作中也只有Fan等(2013)系统研究了 TKL对白 刺花的遗传分化和种群历史等的影响。因此, 楷永 线对两侧其他植物分布的影响以及TKL的生物地理 学意义均需要进一步研究。

\section{3 四川盆地}

四川盆地在中新世中期时(约13 Ma)大体形成 (Liu \& Xu, 2003), 是分布在四川盆地周围植物的主 要遗传屏障, 阻碍种群间的基因流。如Luo等(2011) 使用简单序列重复标记研究了主要分布在四川盆地 周围的第三纪子遗植物珙桐(Davidia involucrata), 表明珙桐种群可分为 4 个群组, 两个分布于盆地西 部, 另外两个分别分布于盆地北部和东部。 $\mathrm{Ma}$ 等 (2015)通过叶绿体基因和核微卫星标记，指出珙桐 可分成以四川盆地为界的东西两个谱系, 在中新世 晚期和上新世交界时(4.81 Ma)分化。在卵叶报春 (Primula ovalifolia)(Xie et al., 2012) 和八角莲 (Dysosma versipellis)(Qiu et al., 2009a; Guan \& Comes, 2010)中也发现了类似的谱系地理间断。在 八角莲中, 东西地区谱系的分化时间在更新世中期 (1.48 Ma), 分化后长时间基因流的缺失表明其可能 处于异域物种形成初期(Qiu et al., 2009a)。由于这些 种的谱系分化时间均明显晚于四川盆地的形成时间， 不同植物的谱系地理结构可能与四川盆地形成引起 的地形和气候变化相关, 而不是由于四川盆地的形 成直接导致的(Ma et al., 2015)。

可以看出, 对四川盆地谱系地理间断形成机制 的关注仍较少。然而, 四川盆地处于中国两个植物 特有属(即分布区域有一定限制的属)分布中心的分 隔线位置, 即川东-鄂西和川西-滇西北中心, 在川 东-鄂西中心的 59 个特有属中, 只有 18 个属与川西滇西北中心共有, 在川西-滇西北中心的 80 个特有 属中, 只有23个属与川东-鄂西中心共有(应俊生和 张志松, 1984)。除四川盆地外, 两特有属分布中心 的分隔线与 TKL也有很好的吻合。那么, 四川盆地 是否作为地理隔离, 还是两特有属分布中心的环境 存在差异, 阻碍了特有属的迁移交流, 尚未得知, 可对两个分布中心的特有属植物进行一系列谱系地 
理工作。

\section{$1.4105^{\circ}$ E附近}

$105^{\circ} \mathrm{E}$ 与中国-日本植物区系中中国-喜马拉雅 亚区(Sino-Himalayan forest subkingdom)和中国-日 本植物亚区(Sino-Japanese forest subkingdom)的分 界线大致吻合(Wu \& Wu, 1996)。中国-喜马拉雅亚 区位于西部高海拔寒冷干燥的地区, 主要受印度季 风影响, 有较低的温带植物物种多样性; 中国-日本 植物亚区在东部低海拔的山地或平原地区主要受太 平洋季风影响, 有较高的温带植物物种多样性(Qiu et al., 2011)。105 $\mathrm{E}$ 可作为谱系地理间断首次是Yan 等(2012)使用叶绿体基因和核转录间隔区在多年生 草本鄂报春(Primula obconica)中发现。随后在很多 其他的植物中相继发现, 包括落叶阔叶林成分(Guo et al., 2014; Cao et al., 2016; Ye et al., 2017)和常绿 阔叶林成分(Sun et al., 2014; Xu et al., 2015), 表明 它是中国-日本植物区系中一个非常重要的谱系地 理间断。然而, 西部地区的遗传多样性并不如预期 的一样比东部地区低, 如在青冈(Cyclobalanopsis glauca)中, 西部地区叶绿体基因的单倍型多样性稍 高于东部地区(Xu et al., 2015); Sun等(2014)使用叶 绿体微卫星揭示栲(Castanopsis fargesii)种群在 $108^{\circ}$ $\mathrm{E}$ 和 $115^{\circ} \mathrm{E}$ 附近存在谱系地理间断, 中部种群的遗 传多样性最高, 西部次之, 东部最低。形成这种模式 的原因可能与地形有关。在中国亚热带地区, 东部 地区多为丘陵地区, 西部有众多的山脉和不适宜生 存的喀斯特地貌，从而在更新世冰期间冰期交替的 过程中, 东部地区有更多的机会在不同种群间发生 基因流, 而西部存在更高的片段化和隔离, 形成较 高的遗传分化, 产生较高的遗传多样性(Shi et al., 2014)。除地形不同外, 其他因素(如世代时间、种群 大小、繁殖系统和扩张能力等)也会影响到遗传多样 性的高低。

除 $105^{\circ} \mathrm{E}$ 以外, 其他谱系地理间断与植物地区 的分界也一致。如MSD与云南高原地区和横断山地 区的分界线一致, 云南高原地区植物基本上是亚热 带性质, 而横断山地区植物是热带亚热带性质; 第 二三级阶梯分界线(见1.5节)将华东地区和华中地区 分开, 约 28 个在某一地区严格特有的特有属和特征 属(两个地区共52个)表明了两个地区间的植物存在 很大差异; 华北地区 (见1.6节)的北面为暖温带针阔 混交林区, 南面为亚热带常绿榈叶林区(吴征镒等,
2010)。植物区系的形成是植物在一定的自然历史环 境中发展演化和时空分布的综合反映。一个特定区 域的植物区系, 不仅反映了这一区域中植物与环境 的因果关系, 同样也反映了植物区系在地质历史时 期中的演化脉络, 往往与大的地质构造线、地貌单 元或气候带相一致(吴征镒等, 2010)。因此, 不同植 物地区间的地理隔离与不同环境可能共同作用, 阻 碍了基因交流, 形成谱系地理间断。由于地理隔离 和不同环境在种群分化和物种形成中的相对重要性 备受关注, 不同植物地区或亚区中分布的植物成为 很好的研究材料。

\section{5 第二三阶梯分界线}

中国的地势自西向东可分为三级阶梯, 第一级 阶梯主要是青藏高原, 一般海拔在4 000-5 $000 \mathrm{~m}$, 第二阶梯以高原、盆地为主, 一般海拔在 1000 $2000 \mathrm{~m}$, 第三阶梯以平原丘陵为主, 一般海拔在 $500 \mathrm{~m}$ 以下, 第二三阶梯的分界线为大兴安岭、太行 山、巫山和雪峰山。很多研究显示第二三阶梯种群 中的等位基因很少存在共享。如在第三纪子遗植物 青钱柳(Cyclocarya paliurus)中, 18 个叶绿体单倍型 组成6个不同的基因谱系, 这些谱系主要局限于第 二阶梯或第三阶梯中(Kou et al., 2016)。化香树 (Platycarya strobilacea)的4个叶绿体基因谱系与青 钱柳有相似的分布模式(Chen et al., 2012)。在野核 桃(Juglans cathayensis)中, 叶绿体基因单倍型在第 二三级阶梯也无共享; 核微卫星最有可能的分组也 为两组, 大致以第二三级阶梯为界, 不过, 两个群 组间基因流较大(Bai et al., 2014)。两个阶梯区域间 无叶绿体单倍型共享的模式在其他植物中也存在 (Lei et al., 2012; Guo et al., 2014; Ying et al., 2016)。 值得注意的是, 虽然第三级阶梯中的山脉一般海拔 在500 m以下, 但是也有高海拔的山峰(>1 $500 \mathrm{~m}$ ), 不同的高海拔山峰往往固定了特有的单倍型, 这可 能是不同山峰的种群间长时间隔离中的遗传漂变作 用导致的。

因此, 第二三级阶梯分界线上的山脉可能作为 扩散屏障, 阻碍了两侧不同种群间的基因流。山脉 在作为扩散屏障的同时, 也可以是植物的扩散廊道, 对物种多样性产生直接的影响(Hoorn et al., 2013)。 中国-日本植物区系的南岭(Wang et al., 2009; Kou et $a l .$, 2016), 大娄山、巫山、清凉峰和大巴山脉(Liu et al., 2013b)以及秦岭山脉(Yuan et al., 2012)等都同时 
扮演着扩散屏障和扩散廊道的角色。王文采(1992a, 1992b)认为中国亚热带地区植物可能起源于西南地 区, 然后向东扩散, 扩散的路线即为北部的秦岭-大 巴山脉、中部的大娄山-武陵山山脉和南部的南岭山 脉。不过, 这个假说只得到较少的验证(Yan et al., 2012; Gong et al., 2015; Ye et al., 2017), 需要更多的 相关研究。另一方面, 山脉的形成同样给地形、流 域和气候等带来巨大变化, 作用于植物演化, 影响 物种多样性。尤其是在一些地质活动频繁的地区, 高山植物通过适应性辐射, 在近期形成了极高的物 种多样性(Hoorn et al., 2013; Hughes \& Atchison, 2015)。如青藏高原的隆起对西南地区的地形和流 域、亚洲内陆干旱以及亚洲季风系统带来深远影响, 该隆起事件对物种多样性的影响已受到了广泛关注 (Wen et al., 2014; Favre et al., 2015)。

\section{6 华北地区}

在第三纪早期温暖湿润的气候条件下, 中高海 拔地区形成了连续分布的混交中生林, 自中新世中 期开始全球大幅度变冷后, 中生林逐步向南退缩形 成第三纪子遗植物区系, 现主要分布于北美、欧洲 西南部和东亚(Tiffney, 1985)。初期, 东亚被认为是 一个单一的、南北连续的第三纪子遗植物避难所 (Tiffney, 1985)。Donoghue等(2001)及Milne和Abbott (2002)则认为东亚第三纪子遗植物区系可分为北方 和南方两个亚区, 两个亚区的形成由一条自西向东 的干旱带(包含华北地区)导致。近期, 多个谱系的地 理学研究为南北两个亚区的划分提供了新证据。

Bai等(2016)使用叶绿体基因、核单拷贝基因和 核微卫星标记以及生态位模型重构了亚洲核桃的谱 系地理历史。三套分子数据都得到两个独特的基因 谱系: 北方谱系, 包括核桃楸(Juglans mandshurica) 和日本核桃(J.ailantifolia); 南方谱系是野核桃种 群。晚上新世时(3 Ma)的生态位模型同样显示南北 种群的潜在分布区无重叠。南北方谱系的分化时间 估计表明中新世晚期时干旱带的重新增强可能触发 了隔离分化事件(Guo et al., 2008)。同时, 南北方种 群间分化后存在的基因流和遗传结构分析显示华北 地区为南北谱系的接触带。表明干旱带虽触发了南 北种群的分化, 但并不足以完全阻止南北谱系间的 基因流。东亚广布种色木槭(Acer mono)的叶绿体基 因和核微卫星数据同样揭示了与亚洲核桃相似的遗 传结构(Guo et al., 2014; Liu et al., 2014)。在两个亚
区存在间断分布的三桠乌药(Lindera obtusiloba)中, Ye等(2017)使用叶绿体和核微卫星数据也发现了南 北方存在两个不同的基因谱系，分化时间估计表明 谱系分化与上新世时干旱带的重新增强相关。并且, 与亚洲核桃和色木棫相比, 在抗旱能力更差的三桠 乌药中, 南北种群的遗传结构更明显、遗传分化水 平更高, 且几乎不存在基因流(Ye et al., 2017)。在这 些例子中, 南北种群的长时间独立演化使南北方种 群形成两个遗传谱系, 并形成了高的遗传分化和相 似的遗传多样性。值得注意的是, 并不是所有第三 纪子遗植物的谱系地理间断位置都位于华北地区, 如Ye等(2015)对色木槭的进一步研究发现, 日本的 色木槭种群与亚热带地区种群有更近的亲缘关系。

Sakaguchi等(2012)发现刺梑(Kalopanax septemlobus) 主要的谱系地理间断位于 $110^{\circ} \mathrm{E}$ 附近。Qi等(2012) 发现虽然连香树属(Cercidiphyllum)植物也存在南北 基因谱系的分化, 但其南部谱系分布在亚热带和日 本南部, 北部谱系分布于华北地区。

上述植物的扩散方式和生活型等各异, 并无明 显规律, 应该不是形成不同遗传格局的主要原因, 主要原因可能是不同植物对干旱条件的耐受性不 同。第三纪子遗植物南北亚区间的干旱带自古新世 以来, 强度慢慢减弱, 现已有一条窄的湿润带 (humid belt)连接南北两个亚区(Guo et al., 2008)。那 么, 有较强耐旱能力植物的南北种群间可以存在基 因流，可能的扩散线路为华北地区的太行山脉(Guo et al., 2014; Bai et al., 2016)。有较差抗旱能力的三桠 乌药的南北种群遗传分化更明显, 几乎不存在基因 流(Ye et al., 2017)。因此, 需要对更多抗旱能力不同 的植物进行研究, 进一步探讨华北地区是否以干旱 带的形式成为重要的谱系地理间断, 将东亚第三纪 子遗植物区系划分为南北两个亚区。

\section{7 东海和朝鲜海峡}

在第四纪冰期时, 海平面下降使陆桥在东海和 朝鲜海峡形成, 作为扩散廊道, 使大陆和岛屿间的 植物呈连续分布。在间冰期时, 海平面上升使陆桥 消失, 大陆和岛屿间植物恢复间断分布。海平面下 降和上升的循环给大陆和岛屿间间断分布的植物提 供了大量接触和再破碎化的机会, 使海峡成为重要 的谱系地理间断。东海和朝鲜海峡作为谱系地理间 断, 主要集中在间断分布于华东、朝鲜半岛和日本 的植物中。 
在小型落叶灌木蛛网荌(Platycrater arguta)中, Qiu等(2009b)发现中国东部和日本南部的种群间无 共享的叶绿体单倍型, 两个种群内的单倍型在网络 图中为两个不同的分组, 分化时间大约为 $0.89 \mathrm{Ma}$ 。 Qi等(2014)进一步发现核基因单倍型在中国和日本 没有共享, 通过叶绿体和核基因的IMa (isolation with migration)分析, 两个种群的分化时间为 0.89 $\mathrm{Ma}$ ，分化过程中的双向基因流几乎为 0 。因此，华东 和日本蛛网墓种群的分化可能由东海陆桥在 $1.0 \mathrm{Ma}$ 的消失触发(Dobson \& Kawahara, 1998), 在分化过 程中, 东海一直扮演着遗传屏障的角色, 维持或加 强了谱系分化, 最终形成两个单系群。在黄精叶钩 吻 (Croomia japonica)(Li et al., 2008)、黄山梅 (Kirengeshoma palmata) 和朝鲜黄山梅 (K. koreana) (Qiu et al., 2009c; Yuan et al., 2014)、鹿蹄䝴吾 (Ligularia hodgsonii)(Wang et al., 2013)以及领春木 属(Euptelea)中也发现了类似的遗传结构和种群动 态历史, 表明东海和朝鲜海峡是重要的谱系地理间 断。不过, 在东亚广布的植物中, 如刺楸(Sakaguchi et al., 2012)、连香树(Qi et al., 2012)等, 东海陆桥都 扮演着扩散廊道的角色。在分布于华北或东北、朝 鲜半岛和日本的植物中, 如鱼鳞云杉(Picea jezoensis) (Aizawa et al., 2007)、核桃楸(Bai et al., 2010)、 日本常绿橡树(Quercus acuta) (Lee et al., 2014)等, 朝鲜海峡陆桥也都扮演着扩散廊道的角色。在上述 研究中, 不同的植物经历了相同的气候变化和海平 面波动, 但不同植物, 甚至是同一植物不同的标记 间能反映出截然不同的种群间谱系关系。因此, 除 了历史地质气候变化外, 植物的生物学特征, 如花 粉和种子传播能力、世代时间及繁殖方式等也必然 对植物谱系分化和遗传结构有重要影响, 导致同一 个谱系地理间断并不在所有植物中共享。

海平面的上升使之前通过陆桥连接的种群重新 间断, 是种群分化和物种形成的重要驱动力。不过, 除东海陆桥和朝鲜海峡陆桥外, 台湾陆桥在种群分 化中的作用少有关注(Chou et al., 2011)。台湾除高 水平的植物多样性和特有性外, 另外一个显著特征 是其与东亚西南地区存在大量间断分布的植物(陈 之端等, 2012)。叶健飞等(2012)通过化石和形态学证 据推测, 台湾和西南地区植物间断分布的来源存在 3种假说, 即北半球温带来源、中国西南来源和热带 亚洲来源假说。谱系地理学方法可准确地估测分化
时间、遗传分化和基因流等，探究更详细的分化历 史和种群动态, 对 3 种起源假说进行进一步验证。对 间断分布植物物种或物种对的研究可探究不同气 候、地理隔离或台湾海峡陆桥的浮现与消失等驱动 力在种群分化和物种形成中的相对贡献, 更深刻地 理解东亚生物多样性的起源和维持机制。

\section{2 谱系地理间断形成机制}

在上述谱系地理研究中, 谱系分化时间最早可 追溯到中新世, 中新世以来的地质气候变化及区域 间不同环境引起的适应性分化共同导致了谱系地理 间断的形成。中新世以来东亚主要的地质事件是青 藏高原隆起, 气候变化包括亚洲季风和内陆干旱的 形成与增强、干旱带的重新增强、全球气温变化和 海平面的升降。这些历史地质事件和气候变化是形 成普遍谱系地理间断的历史因素。虽然上述7个谱系 地理间断多为地理隔离, 但是间断两侧的环境往往 也存在很大差异。如南岭会阻碍东亚夏季季风, 造 成南岭南北环境的差异; 中国-日本植物区系两个 亚区的分界线会阻碍西南的印度季风, 使两个亚区 处于不同季风的影响下。不同环境中不同的选择压 力可能会促使植物产生不同的分化, 即适应性分 化。适应性分化作为生态因素, 对谱系地理间断形 成的作用也不容忽视。

\section{1 历史因素}

\subsection{1 青藏高原隆起}

青藏高原是世界上海拔最高、地域最广的高原。 在谱系地理学、系统发育学和生态学等学科方面, 都有通过青藏高原的特殊地理位置来研究物种间地 理隔离和遗传分化问题的研究。不仅高原本身可作 为遗传屏障触发地理隔离事件, 与青藏高原隆起相 关的一系列气候变化同样是分布区变化和谱系分化 的重要驱动力(Favre et al., 2015)。

青藏高原地处欧亚大陆生物区系分区与植被地 带的中心与枢纽位置, 它是不同生物区系成分分布 的巨大地形障碍, 使欧亚大陆许多区系成分的分布 都止于高原的四周, 使其成为生物分区的自然边界 (中国科学院中国植被图编辑委员会, 2007)。Wen等 (2014)通过对青藏高原不同裸子植物的研究探讨了 物种分化的机制和联系, 在不同的分化路线中, 青 藏高原和横断山脉是地理隔离的主要因素。青藏高 原的隆起始于始新世时印度板块和欧亚大陆间的碰 
撞(Rowley \& Currie, 2006)。关于随后青藏高原隆起 的时间和幅度, 不同的专家根据不同的研究材料和 研究方法提出过不同的观点(Renner, 2016; 周浙昆 等, 2017)。以往谱系地理工作往往认为中新世后的 几次隆起事件与植物的遗传结构和遗传分化相关 (Wang et al., 2015a; Kou et al., 2016; Zhang et al., 2016), 主要是 15 Ma (Spicer et al., 2003)、10-8 Ma (Harrison et al., 1992)、3.6 Ma (An et al., 2001)和 1.1-0.6 Ma (Zhou et al., 2006)时的隆起事件。基于青 藏高原隆起过程的复杂性以及不同专家对隆起时间 与幅度观点的多样性, 今后的谱系地理工作需严谨 地对待植物进化历史与隆起事件的相关性。

青藏高原隆起对东亚地形地貌的影响是冊庸置 疑的。青藏高原隆起使中国的地形地貌从原来的东 高西低变成了西高东低, 形成了三级阶梯地形 (Zhang et al., 2000), 促使植物分布形成了经度上的 分化(Jin et al., 2003)。如Sun等(2014)发现栲在西部、 中部和东部三个谱系的分界线就与第二三阶梯的分 界线和武夷山脉大致一致, 估测的分化时间表明谱 系分化与云贵高原和武夷山在更新世的明显隆起相 吻合。青藏高原的隆起对河流的形成和改变也有巨 大影响, 间接影响植物的分布格局。长江即是随着 高原的隆起而形成的, 是植物重要的扩散屏障 (Gong et al., 2015)。高原隆起对西南地区河流的改 变最为明显, 河流的改变影响了植物不同种群间的 交流, 进而影响了遗传多样性分布和遗传结构 (Zhang \& Sun, 2011)。

\subsection{2 季风}

中国-日本植物区系受印度洋季风和东亚季风 的影响, 东亚季风可分为寒冷干燥的冬季季风和温 暖湿润的夏季季风。夏季印度洋湿润的西南印度洋 季风使印度平原和喜马拉雅山南坡湿度很高, 也影 响了青藏高原东南隅河谷和山地的湿度, 东亚季风 则给东亚大陆带来了丰沛的夏季降雨, 是发育和维 持常绿阔叶林的主导条件(中国科学院中国植被图 编辑委员会, 2007)。季风系统另外一个显著的环境 效应是季节性增强, 形成干湿两季的显著变化。在 长期冬、春季干旱的环境胁迫下, 会导致群落组成 和植被类型的变化(Li et al., 2015)。

亚洲季风的形成可追溯到渐新世晚期至中新世 早期(施雅风等, 1998, 1999; Sun \& Wang, 2005), 其 形成以及随后的增强和减弱与青藏高原隆起和全球
变冷等因素有密切的关系(周浙昆等, 2017)。亚洲季 风的减弱和增强可作为种群分化和种群扩张的重要 驱动力, 在种群历史中扮演重要的作用(Wang et al., 2015b)。季风也可在地理隔离的作用下, 产生不同 的环境, 促进谱系地理间断的形成。如中国亚热带 地区的西部(约 $105^{\circ} \mathrm{E}$ 以西)主要受印度洋季风影响, 东部(约 $105^{\circ} \mathrm{E}$ 以东)主要受东亚季风影响, 东、西部 不同的气候环境促进了位于 $105^{\circ} \mathrm{E}$ 左右的谱系地理 间断的形成。TKL两侧也因不同季风的影响而成为 重要的谱系地理间断, 其西侧为印度和太平洋季风, 东侧主要为太平洋季风( $\mathrm{Li} \& \mathrm{Li}, 1997)$ 。南岭山脉对 季风的阻挡形成了南北气候差异, 同样可促使南岭 南北的植物产生明显的分化(Zhao et al., 2013a)。

\subsection{3 干旱}

水热条件是影响植物生活、生长发育和分布的 主要因素。干旱是影响植物分布的一个重要胁迫因 子, 植物通过适应或者迁移响应干旱化。始新世时, 亚洲有一条很宽的东西向干旱带, 随后慢慢减弱变 窄(施雅风等, 1998), 在中新世晚期和上新世时, 有 重新增强的趋势(Guo et al., 2008)。Milne和Abbott (2002) 以及Donoghue等(2001)提出上述东西向的干 旱带将东亚第三纪子遗植物分为南北两个亚区。近 期，Bai等(2016)对亚洲核桃和Ye等(2017)对三桠乌 药的谱系地理工作进一步证实了此观点。由于干旱 带的宽度和强度的逐渐降低, 现在华北已有一条窄 的湿润带连接南北, 因此, 干旱带对南北地区广布 种谱系分化及其维持或强化的作用可能与物种对干 旱条件的耐受性呈负相关关系。

干旱的另外一个表现是亚洲内陆干旱的形成和 增强, 是伴随着亚洲季风在渐新世晚期中新世早期 的形成而形成的, 随后经历了一系列的增强阶段 (Sun et al., 2010; Zhang et al., 2014)。干旱的形成和 增强与青藏高原隆起、季风和全球变冷等都有密切 的联系(施雅风等, 1999; Lu \& Guo, 2014)。亚洲内陆 的干旱迫使亚洲内陆的植物向南退缩, 在水热条件 更好的亚热带地区寻找合适的栖息地(Dao et al., 2013)。谱系地理研究也表明亚洲内陆干旱和气候变 冷对第三纪子遗植物的近期物种形成有重要作用 (邱英雄等, 2017)。由于亚洲内陆干旱与中国-日本植 物区系位置并不重合, 相比于其他的地质气候事件, 其对该地区植物谱系分化的影响是间接的, 起到的 作用较小。 


\subsection{4 第四纪气候变化}

第三纪初期的气候是温暖湿润的，自渐新世早 期开始逐渐变冷, 尤其自中新世中期时, 开始大幅 度变冷(Zachos et al., 2001), 气候变冷和亚洲内陆 干旱一起, 迫使第三纪初期中高纬度环北分布的温 带植物逐渐向南退缩, 驱使了第三纪子遗植物的近 期物种形成(邱英雄等, 2017)。随后, 上新世初期时 的一次大幅度变冷也促进了种内谱系分化, 影响了 种群动态(Qi et al., 2012; Cao et al., 2016)。最后, 北 半球冰期将全球气候变成“冰窑”, 进入第四纪, 冰 期和间冰期进行周期性交替(Zachos et al., 2001)。第 四纪的气候变化可能是对中国-日本植物区系中植 物影响最大的。Qian和Ricklefs (2000)及Harrison等 (2001)的植被类型重建研究关注的是第四纪冰期, 谱系地理研究也认为动荡的第四纪气候是对分布区 变化和遗传结构影响最大的因素(Qiu et al., 2011; Liu et al., 2012)。

通过化石狍粉对植被的重建可了解不同植被类 型变化的动态过程, 温带落叶阔叶林和亚热带常绿 阔叶林均符合经典的南方避难所模型(southern refugia model)(Yu et al., 2000; Harrison et al., 2001; Ni et al., 2010)。然而, 很多谱系地理研究表明东亚的 植物并不符合经典的南方避难所模型。在温带落叶 阔叶林植物中, 北方避难所已是常见的遗传模式 (Aizawa et al., 2007; Bai et al., 2010, 2016; Zeng et al., 2011)。大面积冰盖的缺失、多样的地形和气候 条件为植物群落的原地保留提供了有利条件。南北 方种群间的地理隔离或不同的环境可能使种群持续 产生分化, 形成两个不同的单系类群(Bai et al., 2016; Ye et al., 2017)。在亚热带常绿阔叶林植物中, 大部分植物都符合多个避难所模型, 并没有经历明 显的南退北进(叶俊伟等, 2017)。如Shi等(2014)发现 优势种甜槠(Castanopsis eyrei) 在西部和东部存在两 个基因库, 两个基因库还存在明显的亚结构; Wang 等(2015a)发现三叶崖爬藤(Tetrastigma hemsleyanum) 在中国西北、华中以及华南和华东地区存在 3 个遗传 分组。在优势种檵木(Loropetalum chinense)中, 虽然 揭示了南方避难所模式和明显向北扩张的种群历史, 同样也发现了多个避难所格局(Gong et al., 2015)。 冰期时, 这些植物在各大山脉中避难, 如横断山脉 和大雪山脉、云贵高原、南岭和华中地区山脉等, 这 些地区在冰期间冰期交替中较小的气候波动为植物
生存提供了有利的条件(Feng et al., 2015)。在冰期寒 冷干燥气候和间冰期温暖湿润气候交替过程中, 植 物群落可能经历了局部地区海拔的上下迁移, 而不 是纬度上的南退北进(Hewitt, 1996)。因此, 东亚植 物在第四纪冰期时, 往往在多个避难所中原地避难, 间冰期时经历有限的扩张。不同避难所种群在冰期 间冰期的交替中长期隔离, 产生分化, 形成谱系地 理间断(Qiu et al., 2011)。此外, 冰期间冰期时冰盖 的变化使海平面经历了下降和上升的交替, 也是形 成谱系地理间断的重要原因(见1.7节)。

虽然很多植物叶绿体基因谱系的分化时间明显 早于第四纪, 但第四纪冰期间冰期的交替对遗传多 样性分布和种群动态历史的影响不容忽视。在探究 近期气候变化的影响时, 突变速率更高的分子标记 (如微卫星)更适合。在冰期间冰期交替影响下的一 个经典问题是南方避难所和北方避难所模型的争 论。就温带落叶阔叶林植物而言, 北方避难所已是 常见的遗传模式(Aizawa et al., 2007; Bai et al., 2010, 2016; Zeng et al., 2011)。对亚热带常绿阔叶林植物 而言, 以往谱系地理工作认为北方避难所的存在是 普遍现象(叶俊伟等, 2017)。近期, Fan等(2016)使用 叶绿体基因比较了 3 种常绿阔叶林植物的谱系地理 历史, 发现红楠(Machilus thunbergii)符合经典的南 方避难所模式。红楠分布于海拔 $800 \mathrm{~m}$ 以下, 位于常 绿阔叶林的基带, 可能对第四纪冰期的气候变化更 为敏感, 通过向南退缩的方式躲避高纬度寒冷干燥 的环境。是否位于基带的常绿阔叶林植物符合南方 避难所模型尚未得知, 需要更多代表类群的研究, 也需要核基因和叶绿体基因间遗传结构和种群历史 的相互验证。

上述地质事件(青藏高原隆起)和气候变化(季 风、干旱)与全球气温变化往往相伴发生, 相互作 用。因此, 以往谱系地理工作往往将植物遗传结构 和遗传分化等归因于不同因素间的共同作用(王丽 娜等, 2012)。在阐述历史地质气候事件与谱系分化 关系的研究中, 往往是通过多个化石校准点对溯祖 时间进行估测，用叶绿体基因的谱系分化时间推测 种群(物种)的种群动态历史。值得注意的是, 单基因 座的遗传信息只可代表随机溯祖过程中的一次, 不 完全的谱系分选使得基因树和种群(物种)树的拓扑 结构并不一致, 导致两者的分化时间并不一致 (Garrick et al., 2015)。实际上，核基因储存了更多的 doi: 10.17521/cjpe.2016.0388 
遗传信息(Hedrick, 1999), 核微卫星、多位点单拷贝 基因甚至基因组信息需越来越广泛地应用于推断种 群分化历史和种群动态历史的研究中。

\section{2 生态因素——适应性分化}

适应性分化是指不同环境中不同的选择压力下 植物产生的不同分化。当产生适应性分化的种群再 次接触时, 生殖隔离或杂交不育等过程可阻碍基因 流, 形成谱系地理间断。在东亚, 地形和气候环境极 其多样, 自南向北具有热带、亚热带至寒温带的气 候梯度性和连续完整的各类植被类型, 自西向东具 有海拔的梯度性和不同的季风环境, 大陆和海岛间 也往往具有不同的环境。不同区域间的异质环境很 有可能形成适应性分化, 在种群分化和物种形成过 程中扮演重要的角色。

以往谱系地理工作使用的是中性标记, 也可以 探测到适应性分化, 因为分化种群间适应性位点的 基因流变化会影响与其连锁中性位点的分化(Nosil et al., 2008)。不同基因谱系与植物性状或者不同环 境间存在高度吻合的情景表明了适应性分化的存 在。如多年生草本植物大叶柴胡(Bupleurum longiradiatum), 分布于秦岭及周围地区的种群花为紫色, 分布于东北和华东地区的种群花为黄色, Zhao等 (2013b)使用叶绿体基因标记发现紫色和黄色花色 的种群为两个单系群, 谱系间没有单倍型共享。在 南北方种群为两个基因谱系的亚洲核桃中, Bai等 (2016)对环境因子进行了主成分分析, 发现南北种 群生存的环境在温度和降水量方面存在显著差异, 环境隔离(isolation by environment, IBE)分析进一步 表明, 在去除地理距离(isolation by distance, IBD)的 影响后, 环境因子的不同显著影响了种群间的遗传 分化, 表明亚洲核桃对南北不同环境的适应在种群 分化中起着重要的作用。不过, 环境的不同并不一 定与遗传分化有必然联系。Cao等(2016)认为中国领 春木(Euptelea pleiosperma) 和日本多花领春木 $(E$. apolyandra)的种群分化由寒冷干燥的气候触发, 种 群分化维持和增强的驱动力是地理隔离(东海), 而 不是由两个区域内显著不同的环境造成。

在使用中性标记的谱系地理研究中, 通过去除 地理隔离的影响, 判断是否存在环境隔离或适应隔 离(isolation by adaptation, IBA), 是检测植物是否存 在适应性分化较为简洁的方法。虽不能揭示形成适 应性分化的功能基因, 存在显著分化基因谱系的分
布模式可作为判断可能适应方向的依据, 提高功能 基因篮选的准确性。如刘建全(2011) ${ }^{\circledR}$ 先通过中性标 记重建了虎榛子属(Ostryopsis) 3个种基因谱系的分 布格局和分化历史, 再使用转录组中表达序列标签 标记(expressed sequence tag, EST)揭示功能基因的 谱系地理格局, 通过中性位点和表达位点遗传格局 的比较, 推测 $F R O$ 基因可能是物种形成的关键基 因。其次, 与地理隔离下有限基因流不同的是, 适应 性分化种群的基因流仅仅在分化位点及与其连锁的 位点受限, 其他中性区域的基因流可能很高(Nosil et al., 2012)。Zhou等(2014)通过中性和适应性位点 间基因流的比较, 篮选出黄山松(Pinus taiwanensis) 和马尾松 (P. massoniana) 中与海拔相关的适应性分 化位点。最后, 已固定的适应性分化位点有很高的 遗传分化，与其连锁的中性位点因 “搭便车” (hitch-hiking)效应也会形成高水平的遗传分化, 与 其他中性位点间的遗传分化存在显著差异(Kim \& Stephan, 2002)。通过对全基因组范围内非连锁位点 间遗传分化水平的比较, 也可以定位存在适应性分 化的位点(Storz, 2005)。

复杂的地质气候历史以及地理隔离和环境隔离 的共同作用导致不同植物间共享相同的谱系地理间 断。不过, 同一个谱系地理间断并不在所有的植物 中共享。不同植物间不同的生物学特征是形成不同 谱系地理间断模式的原因, 其中最重要的是扩散能 力。在植物种群扩散过程中, 种群间的基因流包括 花粉流和种子流。一般而言, 花粉由风传播植物的 基因流往往大于由昆虫传播的。在种子传播的媒介 中, 鸟类比动物、风和重力等有更高的传播距离, 甚 至可以跨越海洋, 从大陆扩散到长距离的海岛上。 除了花粉和种子的传播方式, 其他因素, 如世代时 间、有效种群大小和种子产量等同样可影响扩散能 力(Qi et al., 2014)。在种内, 种子和花粉扩散能力常 常不一致, 使叶绿体和核基因标记往往揭示不一致 的遗传结构(Sakaguchi et al., 2012; Bai et al., 2014; Ye et al., 2015)。在种间, 相比于扩散能力弱的植物, 扩散能力强的植物很有可能跨越其他种的谱系地理 间断(Aizawa et al., 2007; Qi et al., 2014)。植物对干 旱和寒冷等环境适应性的不同也会影响谱系地理结

(1) 刘建全 (2011). 虎榛子属的适应性物种分化、杂交渗入和杂交物 种形成. 全国系统与进化植物学研讨会暨第十届青年学术研讨 会. 昆明. 
构(Bai et al., 2016; Ye et al., 2017)。局限于单个物种 的谱系地理研究并不能很好地解释同一谱系地理间 断不在所有植物中共享的机制, 可扩展到多个物种 的比较谱系地理学。

\section{3 展望}

谱系地理间断的形成与历史地质气候事件密切 相关, 地理隔离和环境隔离在其形成和维持中均起 到了很重要的作用。因此, 我们先从分化时间的准 确估计与地理隔离和环境隔离的相对重要性两个方 面展望未来的发展趋势。然后, 我们将阐述比较谱 系地理学在谱系地理间断研究中的作用。

首先，种群进化历史与地质气候事件之间的关 联取决于谱系分化时间的准确估计。谱系地理工作 中分化时间的估计主要是基于细胞器(叶绿体或线 粒体)基因。单个位点标记只能重建高度随机溯祖过 程的一次, 很难还原种群真实的进化历史。且谱系 分化时间的估计是基于简单的分子钟模型, 不完全 的谱系分选会影响时间估计的准确性。同时, 基因 树和种群(物种)树的拓扑结构并不一致, 使得两者 的分化时间并不一致(Garrick et al., 2015)。因此, 多 方面原因严重影响了细胞器基因对基因谱系分化时 间的准确估计。显而易见, 更多的遗传信息储存在 核基因中, 且核基因往往与细胞器基因所揭示的种 群结构不一致。核微卫星标记因其共显性遗传、多 态性高和突变速率高的特征, 是近期谱系地理工作 中常使用的标记(盛岩等, 2002)。除核微卫星外, 单 拷贝基因(single copy gene)同样可以提供多位点的 序列信息，不过单拷贝的开发存在一定的障碍。第 一, 与核微卫星一样, 需要针对每个物种开发独立 的标记。二代测序技术的发展可为标记的大量开发 提供便利, 如表达序列标签微卫星(EST-SSR)标记 (Zhu et al., 2016)和低拷贝核基因序列引物(Higashi et al., 2015)。第二, 从二倍体杂合子中获得核等位 基因信息大多需要克隆测序, 一个替代的解决方案 是通过分析方法重构二倍体的等位基因信息, 如 PHASE (Stephens et al., 2001)。最后也最严重的问题 是核基因序列中可能存在重组, 会干扰不同谱系间 溯祖过程的正确重建(Avise, 2009)。虽然核基因的使 用存在一些不足, 多位点的分析仍可以提供更多的 遗传信息。通过贝叶斯模型, 可使用核基因对种群 分化时间进行估计, 与基于分子钟估计的谱系分化
时间相结合, 分析种群动态和分化历史与历史地质 气候变化之间的相关性。核微卫星或核单拷贝基因 标记的使用还可与细胞器基因所揭示的种群历史相 互验证。那么, 在今后的谱系地理研究中, 核基因与 细胞质基因的互补必然成为基本要求。

其次, 地理隔离和环境隔离在种群分化和物种 形成过程中的相对贡献尚不明确。以往研究更多关 注的是地理隔离在遗传格局中所起的作用。近期, 气候差异、生态位相似性(niche similarity)和环境隔 离在遗传格局中扮演的角色已逐渐引起重视。如 Zhang等(2016)和 He等(2016)均比较了地理隔离和 环境隔离在遗传分化中的相对贡献度。环境隔离格 局的存在表明物种可能存在适应性分化, 并可以预 测可能的分化方向。不过，少量中性标记的使用无 法定位受选择的位点。可通过中性和适应性分化位 点间基因流的比较, 篎选可能的分化位点(Zhou et al., 2014)。同时，随着二代测序技术的发展，快速低 成本的转录组数据已用于寻找不同环境中存在表达 差异的基因。简化基因组数据也使得大量 SNP (single nucleotide polymorphism)标记的获得变得非 常容易, 可以对基因组非连锁位点的遗传分化进行 分析, 篮选可能存在适应性分化的位点。但值得注 意的是, SNP本质上仍是基因型数据, 在其重复性 和可靠性方面尚存在一定的争议(Arnold et al., 2013)。最后, 全基因组测序和重测序已用于很多模 式种功能基因的研究中。在非模式种中, 简化基因 组或全基因组数据会越来越多地用于种群分化和物 种形成过程和机制的研究中。

然后，比较谱系地理学方法可更深刻地认识谱 系地理间断的形成机制。现在谱系地理工作仍重点 关注单个物种, 需从单个物种向多个物种转变。对 同域分布的多个植物而言, 除可研究历史地质气候 变化是如何影响谱系分化和遗传结构外, 还可判断 除历史因素外的生物学因素是否是造成不同格局的 原因。在东亚, 已开展了少部分的比较谱系地理研 究, 如在喜马拉雅-横断山地区(Luo et al., 2016)、亚 热带地区(Fan et al., 2016)和东北地区(Wang et al., 2016)。虽然在不同地区都有比较谱系地理研究, 但 是这些研究仍局限于少数几个物种, 比较谱系地理 研究在整个谱系地理研究中占的比例太小。植物与 其他生物间的相互关系同样也是比较谱系地理研究 的很好材料, 可从扩散能力或者协同进化的角度来 
研究谱系地理间断的形成机制。

最后，东亚中国-日本植物区系自南向北有多 个气候梯度和连续完整的各类植被类型, 自西向东 有三级阶梯的地形和众多不同走向的山脉, 经历了 青藏高原的剧烈隆起和一系列的气候变化, 海岛和 大陆间存在古老的历史和冰期间冰期交替中的反复 连接和间断，使植物不同基因谱系间的谱系地理间 断普遍存在。随着核基因标记的进一步应用，与其 他学科的进一步结合, 在比较谱系地理学方法的框 架下, 谱系地理学将逐步揭开东亚高水平植物生物 多样性的形成和维持机制。

\section{基金项目 国家自然科学基金(31600301)。}

致谢 浦东新区科技发展基金博士后基金和上海科 技馆引进人才项目资助本研究; 华东师范大学王天 厚教授、北京师范大学王红芳副教授和上海科技馆 蔡荕助理研究员在文章撰写和修改中给予帮助, 谨 致谢忱。

\section{参考文献}

Aizawa M, Yoshimaru H, Saito H, Katsuki T, Kawahara T, Kitamura K, Shi F, Kaji M (2007). Phylogeography of a northeast Asian spruce, Picea jezoensis, inferred from genetic variation observed in organelle DNA markers. Molecular Ecology, 16, 3393-3405.

An ZS, Kutzbach JE, Prell WL, Porter SC (2001). Evolution of Asian monsoons and phased uplift of the Himalaya-Tibetan Plateau since Late Miocene times. Nature, 411, 62-66.

Arnold B, Corbett-Detig RB, Hartl DL, Bomblies K (2013). Radseq underestimates diversity and introduces genealogical biases due to nonrandom haplotype sampling. Molecular Ecology, 22, 3179-3190.

Avise JC (2000). Phylogeography: The History and Formation of Species. Harvard University Press, Cambridge, UK.

Avise JC (2009). Phylogeography: Retrospect and prospect. Journal of Biogeography, 36, 3-15.

Bai WN, Liao WJ, Zhang DY (2010). Nuclear and chloroplast DNA phylogeography reveal two refuge areas with asymmetrical gene flow in a temperate walnut tree from East Asia. New Phytologist, 188, 892-901.

Bai WN, Wang WT, Zhang DY (2014). Contrasts between the phylogeographic patterns of chloroplast and nuclear DNA highlight a role for pollen-mediated gene flow in preventing population divergence in an East Asian temperate tree. Molecular Phylogenetics and Evolution, 81, 37-48.

Bai WN, Wang WT, Zhang DY (2016). Phylogeographic breaks within Asian butternuts indicate the existence of a phyto- geographic divide in East Asia. New Phytologist, 209, 1757-1772.

Cao YN, Comes HP, Sakaguchi S, Chen LY, Qiu YX (2016). Evolution of East Asia's Arcto-tertiary relict Euptelea (Eupteleaceae) shaped by late Neogene vicariance and Quaternary climate change. BMC Evolutionary Biology, 16, 1-17.

Chen SC, Zhang L, Zeng J, Shi F, Yang H, Mao YR, Fu CX (2012). Geographic variation of chloroplast DNA in Platycarya strobilacea (Juglandaceae). Journal of Systematics and Evolution, 50, 374-385.

Chen ZD, Ying JS, Lu AM (2012). Disjunct distribution of seed plants between southwestern China and Taiwan island of China. Chinese Bulletin of Botany, 47, 551-570. (in Chinese with English abstract) [陈之端, 应俊生, 路安民 (2012). 中国西南地区与台湾种子植物间断分布现象. 植物学报, 47, 551-570.]

Chou YW, Thomas PI, Ge XJ, LePage BA, Wang CN (2011). Refugia and phylogeography of Taiwania in East Asia. Journal of Biogeography, 38, 1992-2005.

Coyne JA, Orr HA (2004). Speciation. Sinauer Associates, Sunderland, UK.

Dao K, Chen J, Jin P, Dong C, Yang Y, Xu X, Wu J, Xie S, Lin Z, Sun B (2013). A new material of Lindera (Lauraceae) of the Late Pliocene from Tengchong, Yunnan and the genus’ biogeography significance. Acta Geologica Sinica, 87, 690-706

Dobson M, Kawahara Y (1998). Origin of the Japanese land mammal fauna: Allocation of extant species to historically-based categories. Quaternary Research, 37, 385- 395.

Donoghue MJ, Bell CD, Li J (2001). Phylogenetic patterns in Northern Hemisphere plant geography. International Journal of Plant Sciences, 162, S41-S52.

Fan DM, Hu W, Li B, Morris AB, Zheng M, Soltis DE, Soltis PS, Zhang ZY (2016). Idiosyncratic responses of evergreen broad-leaved forest constituents in China to the Late Quaternary climate changes. Scientific Reports, 6, 31044. doi: 10.1038/srep31044.

Fan DM, Yue JP, Nie ZL, Li ZM, Comes HP, Sun H (2013). Phylogeography of Sophora davidii (Leguminosae) across the "Tanaka-Kaiyong Line" , an important phytogeographic boundary in southwest China. Molecular Ecology, 22, 4270-4288.

Favre A, Päckert M, Pauls SU, Jähnig SC, Uhl D, Michalak I, Muellner-Riehl AN (2015). The role of the uplift of the Qinghai-Tibetan Plateau for the evolution of Tibetan biotas. Biological Reviews, 90, 236-253.

Feng G, Mao L, Sandel B, Swenson NG, Svenning JC (2015). High plant endemism in China is partially linked to reduced glacial-interglacial climate change. Journal of Biogeography, 43, 145-154.

Feng JM, Zhu YY (2010). Tanaka line and its bio-geographical

www.plant-ecology.com 
significance: A further discussion. Chinese Journal of Ecology, 29, 1-7. (in Chinese with English abstract) [冯建 孟, 朱有勇 (2010). 也论“田中线”及其生物地理意义. 生态学杂志, 29, 1-7.]

Gao LM, Möller M, Zhang XM, Hollingsworth ML, Liu J, Mill RR, Gibby M, Li DZ (2007). High variation and strong phylogeographic pattern among cpDNA haplotypes in Taxus wallichiana (Taxaceae) in China and North Vietnam. Molecular Ecology, 16, 4684-4698.

Garrick RC, Bonatelli IAS, Hyseni C, Morales A, Pelletier TA, Perez MF, Rice E, Satler JD, Symula RE, Thomé MTC, Carstens BC (2015). The evolution of phylogeographic datasets. Molecular Ecology, 24, 1164-1171.

Gong W, Liu WZ, Gu L, Kaneko S, Koch MA, Zhang DX (2015). From glacial refugia to wide distribution range: Demographic expansion of Loropetalum chinense (Hamamelidaceae) in Chinese subtropical evergreen broadleaved forest. Organisms Diversity and Evolution, 16, 23-38.

Guan BC, Comes HP (2010). Genetic structure and breeding system of a rare understory herb, Dysosma versipellis (Berberidaceae), from temperate deciduous forests in China. American Journal of Botany, 97, 111-122.

Guo XD, Bao L, Bai WN, Wang HF, Ge JP (2015). Non-random genetic structure revealed by neutral molecular markers in phylogeography researches with special focus on plant species in East Asia. Journal of Beijing Normal University (Natural Science), 5, 511-521. (in Chinese with English abstract) [郭希的, 鲍蕾, 白伟宁, 王红芳, 葛剑平 (2015). DNA中性标记反映的非随机亲缘地理 格局一以东亚植物物种为例. 北京师范大学学报: 自 然科学版, 5, 511-521.]

Guo XD, Wang HF, Bao L, Wang TM, Bai WN, Ye JW, Ge JP (2014). Evolutionary history of a widespread tree species Acer mono in East Asia. Ecology and Evolution, 4, 43324345.

Guo ZT, Sun B, Zhang ZS, Peng SZ, Xiao GQ, Ge JY, Hao QZ, Qiao YS, Liang MY, Liu JF (2008). A major reorganization of Asian climate by the early Miocene. Climate of the Past, 4, 153-174.

Harrison SP, Yu G, Takahara H, Prentice IC (2001). Palaeovegetation: Diversity of temperate plants in East Asia. Nature, 413, 129-130.

Harrison TM, Copeland P, Kidd WS, Yin A (1992). Raising Tibet. Science, 255, 1663-1670.

He K, Jiang XL (2014). Sky islands of southwest China. I: An overview of phylogeographic patterns. Science Bulletin, 12, 1055-1068. (in Chinese) [何锴, 蒋学龙 (2014). 中国 西南地区的“天空之岛”: I 系统地理学研究概述. 科学 通报, 12, 1055-1068.]

He SL, Wang YS, Li DZ, Yi TS (2016). Environmental and historical determinants of patterns of genetic differentiation in wild soybean (Glycine soja Sieb. et Zucc). Scientific Reports, 6, 22795. doi: 10.1038/srep22795.

Hedrick PW (1999). Perspective: Highly variable loci and their interpretation in evolution and conservation. Evolution, 53, 313-318.

Hewitt GM (1996). Some genetic consequences of ice ages, and their role in divergence and speciation. Biological Journal of the Linnean Society, 58, 247-276.

Hickerson MJ, Carstens BC, Cavender-bares J, Crandall KA, Graham CH, Johnson JB, Rissler L, Victoriano PF, Yoder AD (2010). Phylogeography's past, present, and future: 10 years after Avise, 2000. Molecular Phylogenetics and Evolution, 54, 291-301.

Higashi H, Ikeda H, Setoguchi H (2015). Molecular phylogeny of Shortia sensu lato (Diapensiaceae) based on multiple nuclear sequences. Plant Systematics and Evolution, 301, 523-529.

Hoorn C, Mosbrugger V, Mulch A, Antonelli A (2013). Biodiversity from mountain building. Nature Geoscience, 6, 154.

Hughes CE, Atchison GW (2015). The ubiquity of alpine plant radiations: From the Andes to the Hengduan Mountains. New Phytologist, 207, 275-282.

Jin J, Liao W, Wang B, Peng S (2003). Global change in Cenozoic and evolution of flora in China. Guihaia, 23, 217225.

Kim Y, Stephan W (2002). Detecting a local signature of genetic hitchhiking along a recombining chromosome. Genetics, 160, 765.

Kou YX, Cheng SM, Tian S, Li B, Fan DM, Chen YJ, Soltis DE, Soltis PS, Zhang ZY (2016). The antiquity of Cyclocarya paliurus (Juglandaceae) provides new insights into the evolution of relict plants in subtropical China since the late Early Miocene. Journal of Biogeography, 43, 351360.

Lang KY (1994). Studies on the distribution patterns of some significant genera in orchid flora. Acta Phytotaxonomica Sinica, 32, 328-339. (in Chinese with English abstract) [郎 楷永 (1994). 兰科植物区系中一些有意义属的地理分 布格局的研究. 植物分类学报, 32, 328-339.]

Lee JH, Lee DH, Choi IS, Choi BH (2014). Genetic diversity and historical migration patterns of an endemic evergreen oak, Quercus acuta, across Korea and Japan, inferred from nuclear microsatellites. Plant Systematics and Evolution, 300, 1913-1923.

Lei M, Wang Q, Wu ZJ, López-Pujol J, Li DZ, Zhang ZY (2012). Molecular phylogeography of Fagus engleriana (Fagaceae) in subtropical China: Limited admixture among multiple refugia. Tree Genetics and Genomes, 8, 1203-1212.

Li EX, Yi S, Qiu YX, Guo JT, Comes HP, Fu CX (2008). Phylogeography of two East Asian species in Croomia 
(Stemonaceae) inferred from chloroplast DNA and ISSR fingerprinting variation. Molecular Phylogenetics and Evolution, 49, 702-714.

Li SF, Mao LM, Spicer RA, Lebreton-Anberrée J, Su T, Sun M, Zhou ZK (2015). Late Miocene vegetation dynamics under monsoonal climate in southwestern China. Palaeogeography Palaeoclimatology Palaeoecology, 425, 14-40.

Li XW, Li J (1992). On the validity of Tanaka line \& its sigificance viewed from the distribution of Eastern Asiatic genera in Yunnan. Acta Botanica Yunnanica, 14, 1-12. (in Chinese with English abstract) [李锡文, 李捷 (1992). 从 滇产东亚属的分布论述 “田中线” 的真实性和意义. 云南 植物研究, 14, 1-12.]

Li XW, Li J (1997). The Tanaka-Kaiyong line-An important floristic line for the study of the flora of East Asia. Annals of the Missouri Botanical Garden, 84, 888-892.

Li Y, Zhai SN, Qiu YX, Guo YP, Ge XJ, Comes HP (2011). Glacial survival east and west of the "Mekong-Salween Divide" in the Himalaya-Hengduan Mountains region as revealed by AFLPs and cpDNA sequence variation in Sinopodophyllum hexandrum (Berberidaceae). Molecular Phylogenetics and Evolution, 59, 412-424.

Liu CP, Tsuda Y, Shen HL, Hu LJ, Saito Y, Ide Y (2014). Genetic structure and hierarchical population divergence history of Acer mono var. mono in south and northeast China. PLOS ONE, 9, e87187. doi: 10.1371/journal.pone.0087187.

Liu J, Möller M, Provan J, Gao LM, Poudel RC, Li DZ (2013a). Geological and ecological factors drive cryptic speciation of yews in a biodiversity hotspot. New Phytologist, 199, 1093-1108.

Liu JQ, Sun YS, Ge XJ, Gao LM, Qiu YX (2012). Phylogeographic studies of plants in China: Advances in the past and directions in the future. Journal of Systematics and Evolution, 50, 267-275.

Liu W, Kang M, Tian H, Huang H (2013b). A range wide geographic pattern of genetic diversity and population structure of Castanea mollissima populations inferred from nuclear and chloroplast microsatellites. Tree Genetics and Genomes, 9, 975-987.

Liu Y, Xu C (2003). Modeling for the burial and subsidence history of the Sichuan basin. Chinese Journal of Geophysics, 46, 283-290.

Lu HY, Guo ZT (2014). Evolution of the monsoon and dry climate in East Asia during late Cenozoic: A review. Science China: Earth Sciences, 57, 70-79.

Luo D, Yue JP, Sun WG, Xu B, Li ZM, Comes HP, Sun H (2016). Evolutionary history of the subnival flora of the Himalaya-Hengduan Mountains: First insights from comparative phylogeography of four perennial herbs. Journal of Biogeography, 43, 31-43.

Luo S, He Y, Ning G, Zhang J, Ma G, Bao M (2011). Genetic diversity and genetic structure of different populations of the endangered species Davidia involucrata in China detected by inter-simple sequence repeat analysis. Trees, 25, 1063-1071.

Ma Q, Du Y, Chen N, Zhang L, Li J, Fu CX (2015). Phylogeography of Davidia involucrata (Davidiaceae) inferred from cpDNA haplotypes and nSSR data. Systematic Botany, 40, 769-810.

Meng L, Chen G, Li Z, Yang Y, Wang Z, Wang L (2015). Refugial isolation and range expansions drive the genetic structure of Oxyria sinensis (Polygonaceae) in the Himalaya-Hengduan Mountains. Scientific Reports, 5, 10396. doi: 10.1038/srep10396.

Milne RI, Abbott RJ (2002). The origin and evolution of Tertiary relict floras. Advances in Botanical Research, 38, 281-314.

Myers N, Mittermeier RA, Mittermeier CG, Da FG, Kent J (2000). Biodiversity hotspots for conservation priorities. Nature, 403, 853-858.

Ni J, Yu G, Harrison SP, Prentice IC (2010). Palaeovegetation in China during the late Quaternary: Biome reconstructions based on a global scheme of plant functional types. Palaeogeography Palaeoclimatology Palaeoecology, 289, 44-61.

Nosil P, Egan SP, Funk DJ (2008). Heterogeneous genomic differentiation between walking-stick ecotypes: "Isolation by adaptation” and multiple roles for divergent selection. Evolution, 62, 316-336.

Nosil P, Parchman TL, Feder JL, Gompert Z (2012). Do highly divergent loci reside in genomic regions affecting reproductive isolation? A test using next-generation sequence data in timema stick insects. BMC Evolutionary Biology, 12, 164-176.

Qi XS, Chen C, Comes HP, Sakaguchi S, Liu YH, Tanaka N, Sakio H, Qiu YX (2012). Molecular data and ecological niche modelling reveal a highly dynamic evolutionary history of the East Asian Tertiary relict Cercidiphyllum (Cercidiphyllaceae). New Phytologist, 196, 617-630.

Qi XS, Yuan N, Comes HP, Sakaguchi S, Qiu YX (2014). A strong "filter" effect of the East China Sea land bridge for East Asia's temperate plant species: Inferences from molecular phylogeography and ecological niche modelling of Platycrater arguta (Hydrangeaceae). BMC Evolutionary Biology, 14, 14-41.

Qian H, Ricklefs RE (2000). Large-scale processes and the Asian bias in species diversity of temperate plants. Nature, 407, 180-182.

Qiu YX, Fu CX, Comes HP (2011). Plant molecular phylogeography in China and adjacent regions: Tracing the genetic imprints of Quaternary climate and environmental change in the world's most diverse temperate flora. Molecular Phylogenetics and Evolution, 59, 225-244.

Qiu YX, Guan BC, Fu CX, Comes HP (2009a). Did glacials

www.plant-ecology.com 
and/or interglacials promote allopatric incipient speciation in East Asian temperate plants? Phylogeographic and coalescent analyses on refugial isolation and divergence in Dysosma versipellis. Molecular Phylogenetics and Evolution, 51, 281-293.

Qiu YX, Lu QX, Zhang YH, Cao YN (2017). Phylogeography of East Asia's Tertiary relict plants: Current progress and future prospects. Biodiversity Science, 25, 136-146. (in Chinese with English abstract) [邱英雄, 鹿启祥, 张永华, 曹亚男 (2017). 东亚第三纪子遗植物的亲缘地理学: 现状与趋势. 生物多样性, 25, 136-146.]

Qiu YX, Qi XS, Jin XF, Tao XY, Fu CX, Naiki A, Comes HP (2009b). Population genetic structure, phylogeography, and demographic history of Platycrater arguta (Hydrangeaceae) endemic to east China and south Japan, inferred from chloroplast DNA sequence variation. Taxon, 58, 1226-1241.

Qiu YX, Sun Y, Zhang XP, Lee J, Fu CX, Comes HP (2009c). Molecular phylogeography of East Asian Kirengeshoma (Hydrangeaceae) in relation to Quaternary climate change and landbridge configurations. New Phytologist, 183, 480-495.

Renner SS (2016). Available data point to a 4-km-high Tibetan Plateau by $40 \mathrm{Ma}$, but 100 molecular-clock papers have linked supposed recent uplift to young node ages. Journal of Biogeography, 43, 1479-1487.

Rowley DB, Currie BS (2006). Palaeo-altimetry of the late Eocene to Miocene Lunpola basin, central Tibet. Nature, 439, 677-681.

Royden LH, Clark BB, Hilst RDVD (2008). The geological evolution of the Tibetan Plateau. Science, 321, 1054-1058.

Sakaguchi S, Qiu YX, Liu YH, Qi XS, KIM SH, Takeuchi Y, Worth JR, Yamasaki M, Sakurai S (2012). Climate oscillation during the Quaternary associated with landscape heterogeneity promoted allopatric lineage divergence of a temperate tree Kalopanax septemlobus (Araliaceae) in East Asia. Molecular Ecology, 21, 3823-3838.

Sheng Y, Zheng WH, Pei KQ, Ma KP (2002). Applications of microsatellites in population biology. Acta Phytoecologica Sinica, 26, 119-126. (in Chinese with English abstract) [盛 岩, 郑蔚虹, 裴克全, 马克平 (2002). 微卫星标记在种 群生物学研究中的应用. 植物生态学报, 26, 119-126.]

Shi MM, Michalski SG, Welk E, Chen XY, Durka W (2014). Phylogeography of a widespread Asian subtropical tree: Genetic east-west differentiation and climate envelope modelling suggest multiple glacial refugia. Journal of Biogeography, 41, 1710-1720.

Shi YF, Li JJ, Li BY, Yao TD, Wang SM, Li SJ, Cui ZJ, Wang FB, Pan BT, Fang XM, Zhang QS (1999). Uplift of the Qinghai-Xizang (Tibetan) Plateau and East Asia environmental change during late Cenozoic. Acta Geographica Sinica, 54, 10-21. (in Chinese with English abstract) [施雅
风, 李吉均, 李炳元, 姚檀栋, 王苏民, 李世杰, 崔之 久, 王富保, 潘保田, 方小敏, 张青松 (1999). 晚新生 代青藏高原的隆升与东亚环境变化. 地理学报, 54, 10-21.]

Shi Y F, Tang MC, Ma YZ (1998). The relationship of the second phase uplift of Qinghai-Xizang Plateau with the inoculation of Asian monsoon. Science in China: Earth Sciences, 28, 263-271. (in Chinese) [施雅风, 汤惁苍, 马玉 贞 (1998). 青藏高原二期隆升与亚洲季风孕育关系探 讨. 中国科学: 地球科学, 28, 263-271.]

Spicer RA, Harris NB, Widdowson M, Herman AB, Guo S, Valdes PJ, Wolfe JA, Kelley SP (2003). Constant elevation of southern Tibet over the past 15 million years. $\mathrm{Na}$ ture, 421, 622-624.

Stephens M, Smith NJ, Donnelly P (2001). A new statistical method for haplotype reconstruction from population data. The American Journal of Human Genetics, 68, 978-989.

Storz JF (2005). Invited review: Using genome scans of DNA polymorphism to infer adaptive population divergence. Molecular Ecology, 14, 671-688.

Sun JM, Ye J, Wu WY, Ni XJ, Bi SD, Zhang ZQ, Liu WM, Meng J (2010). Late Oligocene-Miocene mid-latitude aridification and wind patterns in the Asian interior. Geology, 38, 515-518.

Sun XJ, Wang PX (2005). How old is the Asian monsoon system? Palaeobotanical records from China. Palaeogeography Palaeoclimatology Palaeoecology, 222, 181-222.

Sun Y, Hu H, Huang H, Vargas-Mendoza CF (2014). Chloroplast diversity and population differentiation of Castanopsis fargesii (Fagaceae): A dominant tree species in evergreen broad-leaved forest of subtropical China. Tree Genetics and Genomes, 10, 1531-1539.

Tanaka T (1954). Species Problem in Citrus. Japanese Society for Promotion of Science, Ueno, Tokyo.

The Editorial Committee of Vegetation Map of China, Chinese Academy of Sciences (2007). Vegetation Map of the People's Republic of China 1:1000000. Geological Publishing House, Beijing. (in Chinese) [中国科学院中国植被图编 辑委员会 (2007). 中华人民共和国植被图(1:1000000). 地质出版社, 北京.]

Tian B, Zhou Z, Du FK, He C, Xin P, Ma H (2015). The Tanaka line shaped the phylogeographic pattern of the cotton tree (Bombax ceiba) in southwest China. Biochemical Systematics and Ecology, 60, 150-157.

Tiffney BH (1985). Perspectives on the origin of the floristic similarity between Eastern Asia and Eastern North America. Journal of the Arnold Arboretum (USA), 66, 73-94.

Wang J, Gao P, Kang M, Lowe AJ, Huang H (2009). Refugia within refugia: The case study of a canopy tree (Eurycorymbus cavaleriei) in subtropical China. Journal of Biogeography, 36, 2156-2164.

Wang JF, Gong X, Chiang YC, Kuroda C (2013). Phylogenetic 
patterns and disjunct distribution in Ligularia hodgsonii hook. (Asteraceae). Journal of Biogeography, 40, 17411754.

Wang LN, Jiang XL, Lei Y, Zhang ML (2012). A panbiogeographical explanation of the disjunct distribution of Fagus (Fagaceae) in the northern temperate zone. Chinese Journal of Plant Ecology, 36, 393-402. (in Chinese with English abstract) [王丽娜, 姜小龙, 雷耘, 张明理 (2012). 北温带水青冈属的间断分布及其泛生物地理学 解释. 植物生态学报 36, 393-402.]

Wang SH, Bao L, Wang TM, Wang HF, Ge JP (2016). Contrasting genetic patterns between two coexisting Eleutherococcus species in northern China. Ecology and Evolution, 6, 3311-3324.

Wang WM (1994). Paleofloristic and paleoclimatic implications of Neogene palynofloras in China. Review of $\mathrm{Pa}$ laeobotany and Palynology, 82, 239-250.

Wang WT (1992a). On some distribution patterns and some migration routes found in the eastern Asiatic region. Acta Phytotaxonomica Sinica, 30, 1-24. (in Chinese with English abstract) [王文采 (1992a). 东亚植物区系的一些分 布式样和迁移路线. 植物分类学报, 30, 1-24.]

Wang WT (1992b). On some distribution patterns and some migration routes found in the eastern Asiatic region (Cont.). Acta Phytotaxonomica Sinica, 30, 97-117. (in Chinese with English abstract) [王文采 (1992b). 东亚植 物区系的一些分布式样和迁移路线(续). 植物分类学报, 30, 97-117.]

Wang YH, Jiang WM, Comes HP, Hu FS, Qiu YX, Fu CX (2015a). Molecular phylogeography and ecological niche modelling of a widespread herbaceous climber, Tetrastigma hemsleyanum (Vitaceae): Insights into Plio-Pleistocene range dynamics of evergreen forest in subtropical China. New Phytologist, 206, 852-867.

Wang ZW, Chen ST, Nie ZL, Zhang JW, Zhou Z, Deng T, Sun $\mathrm{H}$ (2015b). Climatic factors drive population divergence and demography: Insights based on the phylogeography of a riparian plant species endemic to the Hengduan mountains and adjacent regions. PLOS ONE, 10, e0145014. doi: 10.1371/journal.pone.0145014.

Wen J, Zhang JQ, Nie ZL, Zhong Y, Sun H (2014). Evolutionary diversifications of plants on the Qinghai-Tibetan Plateau. Frontiers in Genetics, 5, 1-16.

Wu ZY, Wu SG (1996). A proposal for a new floristic kingdom (realm): The E. Asiatic kingdom, its delimitation and characteristics. In: Zhang AL, Wu SG eds. Proceedings of the First International Symposium on Floristic Characteristics and Diversity of East Asian Plants. Higher Education Press, Beijing.

Wu ZY, Sun H, Zhou ZK, Li DZ, Peng H (2010). Floristics of Seed Plants from China. Science Press, Beijing. (in Chinese) [ 吴征镒, 孙航, 周浙昆, 李德铢, 彭华 (2010). 中
国种子植物区系地理. 科学出版社, 北京.]

Xie XF, Yan HF, Wang FY, Ge XJ, Hu CM, Hao G (2012). Chloroplast DNA phylogeography of Primula ovalifolia in central and adjacent southwestern China: Past gradual expansion and geographical isolation. Journal of Systematics and Evolution, 50, 284-294.

Xu J, Deng M, Jiang XL, Westwood M, Song YG, Turkington R (2015). Phylogeography of Quercus glauca (Fagaceae), a dominant tree of east Asian subtropical evergreen forests, based on three chloroplast DNA interspace sequences. Tree Genetics and Genomes, 1, 1-17.

Yan HF, Zhang CY, Wang FY, Hu CM, Ge XJ, Hao G (2012). Population expanding with the phalanx model and lineages split by environmental heterogeneity: A case study of Primula obconica in subtropical China. PLOS ONE, 7, e41315. doi: 10.1371/journal.pone.0041315.

Ye JF, Chen ZD, Liu B, Qin HN, Yang Y (2012). Disjunct distribution of vascular plants between southwestern area and Taiwan area in China. Biodiversity of Science, 20, 482-494. (in Chinese with English abstract) [叶建飞, 陈 之端, 刘冰, 覃海宁, 杨永 (2012). 中国西南与台湾地 区维管植物的间断分布格局及形成机制. 生物多样性, 20, 482-494.]

Ye JW, Bai WN, Bao L, Wang TM, Wang HF, Ge JP (2017). Sharp genetic discontinuity in the aridity-sensitive species Lindera obtusiloba (Lauraceae): Solid evidence supporting the Tertiary floral subdivision in East Asia. Journal of Biogeography, 44, 2082-2095.

Ye JW, Guo XD, Wang SH, Bai WN, Bao L, Wang HF, Ge JP (2015). Molecular evidence reveals a closer relationship between Japanese and mainland subtropical specimens of a widespread tree species, Acer mono. Biochemical Systematics and Ecology, 60, 143-149.

Ye JW, Zhang Y, Wan XJ (2017). Phylogeographic history of broad-leaved forest plants in subtropical China. Acta Ecologica Sinica, 37, doi: 10.5846/stxb201606031072. (in Chinese with English abstract) [叶俊伟, 张阳, 王晓娟 (2017). 中国亚热带地区阔叶林植物的谱系地理历史. 生态学报, 37, 5894-5904.]

Ying TS, Zhang ZS (1984). Endemism in the flora of China-Studies on the endemic genera. Acta Phytotaxonomica Sinica, 22, 259-268. (in Chinese with English abstract) [应俊生, 张志松 (1984). 中国植物区系中的 特有现象一特有属的研究. 植物分类学报, 22, 259268.]

Ying LX, Zhang TT, Chiu CA, Chen TY, Luo SJ, Chen XY, Shen ZH (2016). The phylogeography of Fagus hayatae (Fagaceae): Genetic isolation among populations. Ecology and Evolution, 6, 2805-2816.

Yu G, Chen X, Ni J, Cheddadi R, Guiot J, Han H, Harrison SP, Huang C, Ke M, Kong Z (2000). Palaeovegetation of China: A pollen data-based synthesis for the mid-Holocene

www.plant-ecology.com 
and last Glacial Maximum. Journal of Biogeography, 27, 635-664.

Yuan JH, Cheng FY, Zhou SL (2012). Genetic structure of the tree peony (Paeonia rockii) and the Qinling mountains as a geographic barrier driving the fragmentation of a large population. PLOS ONE, 7, e34955. doi: 10.1371/journal.pone.0034955.

Yuan N, Sun Y, Comes HP, Fu CX, Qiu YX (2014). Understanding population structure and historical demography in a conservation context: Population genetics of the endangered Kirengeshoma palmata (Hydrangeaceae). American Journal of Botany, 101, 521-529.

Zachos J, Pagani M, Sloan L, Thomas E, Billups K (2001). Trends, rhythms, and aberrations in global climate $65 \mathrm{Ma}$ to present. Science, 292, 686-693.

Zeng YF, Liao WJ, Petit RJ, Zhang DY (2011). Geographic variation in the structure of oak hybrid zones provides insights into the dynamics of speciation. Molecular Ecology, 20, 4995-5011.

Zhang D, Fengquan L, Jianmin B (2000). Eco-environmental effects of the Qinghai-Tibet Plateau uplift during the Quaternary in China. Environmental Geology, 39, 1352-1358.

Zhang TC, Sun H (2011). Phylogeographic structure of Terminalia franchetii (Combretaceae) in southwest China and its implications for drainage geological history. Journal of Plant Research, 124, 63-73.

Zhang YB, Sun DH, Li ZJ, Wang F, Wang X, Li BF, Guo F, Wu S (2014). Cenozoic record of aeolian sediment accumulation and aridification from Lanzhou, China, driven by Tibetan Plateau uplift and global climate. Global and Planetary Change, 120, 1-15.

Zhang YH, Wang IJ, Comes HP, Hua P, Qiu YX (2016). Contributions of historical and contemporary geographic and environmental factors to phylogeographic structure in a Tertiary relict species, Emmenopterys henryi (Rubiaceae). Scientic Reports, 6, 24041. doi: 10.1038/srep24041.
Zhao C, Wang CB, Ma XG, Liang QL, He XJ (2013a). Phylogeographic analysis of a temperate-deciduous forest restricted plant (Bupleurum longiradiatum Turcz.) reveals two refuge areas in China with subsequent refugial isolation promoting speciation. Molecular Phylogenetics and Evolution, 68, 628-643.

Zhao Y, Vrieling K, Liao H, Xiao MQ, Zhu YQ, Rong J, Zhang WJ, Wang YG, Yang J, Chen JK. (2013b). Are habitat fragmentation, local adaptation and isolation-by-distance driving population divergence in wild rice Oryza rufipogon? Molecular Ecology, 22, 5531-5547.

Zhao Y, Zhang L (2015). The phylogeographic history of the self-pollinated herb Tacca chantrieri (Dioscoreaceae) in the tropics of mainland southeast Asia. Biochemical Systematics and Ecology, 58, 139-148.

Zhou S, Wang X, Wang J, Xu L (2006). A preliminary study on timing of the oldest Pleistocene glaciation in Qinghai-Tibetan Plateau. Quaternary International, 154, 44- 51.

Zhou YF, Zhang LR, Liu JQ, Wu GL, Savolainen O (2014). Climatic adaptation and ecological divergence between two closely related pine species in southeast China. Molecular Ecology, 23, 3504-3522.

Zhou ZK, Huang J, Ding WN (2017). The impact of major geological events on Chinese flora. Biodiversity Science, 25, 123-135. (in Chinese with English abstract) [周浙昆, 黄健, 丁文娜 (2017). 若干重要地质事件对中国植物区 系形成演变的影响. 生物多样性, 25, 123-135.]

Zhu SS, Ding YP, Yap ZY, Qiu YX (2016). De novo assembly and characterization of the floral transcriptome of an economically important tree species, Lindera glauca (Lauraceae), including the development of EST-SSR markers for population genetics. Molecular Biology Reports, 43, 1243-1250.

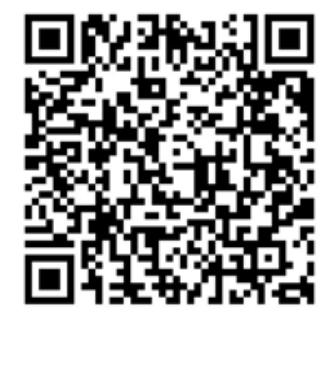

